Obere Extremität 2021 · 16:16-21 https://doi.org/10.1007/s11678-021-00631-2 Received: 15 December 2020

Accepted: 27 January 2021

Published online: 4 March 2021

(c) The Author(s) 2021

\section{Introduction}

Anterior shoulder dislocations produce characteristic anteroinferior capsulolabral injuries that are commonly treated with arthroscopic repair; however, the presence of bone loss either on the glenoid or humeral head can lead to failure of an arthroscopic repair in up to $67 \%$ of cases [1]. Glenoid pathology has been reported in up to $95 \%$ of patients with anterior shoulder instability [2]. Following recurrence of instability, 72\% present with glenoid lesions and $88 \%$ with Hill Sachs lesions [3]. Emerging evidence indicates that bipolar lesions that are each below critical values can also contribute to failure of arthroscopic repair $[4,5]$. Recognition of these defects in guiding treatment is paramount to success in the treatment of shoulder instability. Advancements in the understanding of the glenohumeral joint and its stabilizers, as well as imaging technology, have facilitated recognition of these defects as risk factors for failure.

\section{History and imaging}

The initial evaluation of anterior instability involves a proper history, physical exam, and imaging. Critical factors to obtain in history include age, number of dislocations, dislocations at night, and type and level of sport. Younger age of less than 22 years is recognized as a strong predictor of recurrent instability following isolated arthroscopic Bankart repair $[6,7]$. Dislocation frequency has been shown to be associated with severity of

Rafael Kakazu • Matthew R. LeVasseur • Robert A. Arciero • Augustus D. Mazzocca

Department of Orthopaedic Surgery, University of Connecticut, Farmington, USA

\title{
State of the art for treatment of bony defects around anterior shoulder instability- the American perspective
}

glenoid bone loss, which guides treatment $[8,9]$. A recent prospective study by Dickens et al. evaluated the effect of a single instability event on the amount of glenoid bone among patients with firsttime and recurrent instability in young active patients [10]. The study reported that an initial dislocation event can result in $6.8 \%$ glenoid bone loss, while recurrent instability patients can lose $22.8 \%$. These findings support early stabilization in this population to provide stability and prevent continued erosion of glenoid bone stock. Additionally, dislocation episodes at night with minimal effort would indicate the presence of bone loss. The type and level of sports are each independently associated with recurrent instability following arthroscopic Bankart repair [1]. Competitive athletes and athletes in collision overhead sports are at greater risk for failure. The physical exam may be limited due to pain and apprehension in an acute setting; however, based on the authors' experience, patients with significant bone loss may demonstrate a positive apprehension sign at lower angles of abduction and external rotation. Standard imaging should begin with orthogonal views of the shoulder including anteroposterior (AP), axillary, and West Point views to evaluate overall alignment, bone stock, and fracture. Loss of the anteroinferior glenoid contour or a visible Hill Sachs lesion should raise strong suspicion for significant bone loss. For further evaluation of bone loss, advanced imaging is strongly recommended. Computed tomography (CT) with three-dimensional (3D) subtraction views of the glenoid and humerus provide an accurate evaluation of bone loss. At the authors' institution, for a young (age $<40$ years) patient with anterior instability with low probability of a rotator cuff tear, the preference is for CT scan. Collectively, the initial evaluation helps define the best treatment for the patient.

\section{Evaluating bone loss}

Up to $95 \%$ of patients with anterior shoulder instability present with glenoid pathology [11]. In recurrent instability cases, $72 \%$ may have glenoid defects and $88 \%$ Hill Sachs lesions. In Nakagawa's series, $29.8 \%$ of primary instability patients presented with bipolar lesions; after recurrence, $72 \%$ of patients presented with bipolar lesions [3].

Measurement techniques of glenoid bone loss are variable and range from descriptors of the shape of glenoid to surface area measurements. Nonetheless, it is important to evaluate bone loss with a technique that is consistent and accurate. Glenoid bone loss can be evaluated by overall glenoid morphology, illustrated by Burkhart, or by glenoid height and width to calculate bone loss [1, 12]. The authors' institution favors the best-fit circle technique in which a circle is placed over the inferior glenoid on a sagittal view [13]. From this view, the width of bone loss orthogonal to the glenoid's longitudinal axis can be divided by the circle's diameter to calculate the percentage of glenoid bone loss (• Fig. 1). Critical bone loss, based on cadaveric studies, has previously been defined for the glenoid to 


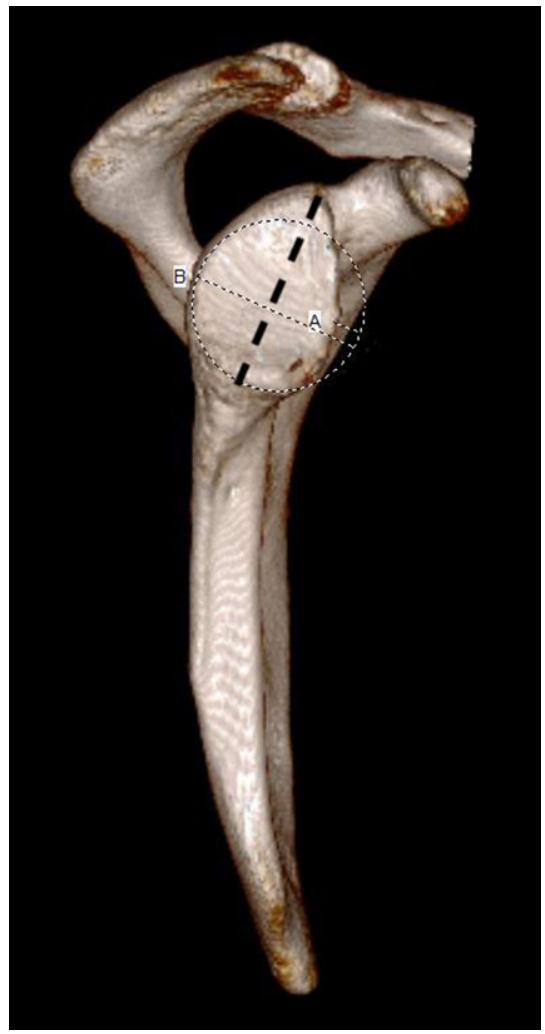

Fig. $1 \Delta$ Three-dimensional en face view of a glenoid with anterior instability. Measurement $A$ denotes the amount of bone loss, whereas $B$ demonstrates the expected width of the glenoid. Dividing $A$ by $B$ calculates the fraction of bone loss

be $20-25 \%$ [1, 14-16]; however, recent studies have redefined this value. In their clinical study, Shaha et al. showed that glenoid bone loss of $13.5 \%$ is associated with poor outcomes following isolated arthroscopic Bankart repair, even in the absence of recurrent instability [4]. Dickens also reported a critical value of $13.5 \%$ among a cohort of intercollegiate American football players [5].

Our understanding of the Hill Sachs lesion also continues to evolve. Burkhart described the concept of the engaging Hill Sachs in which the long axis of the lesion is parallel to the anterior glenoid with the shoulder in abduction and external rotation [1]. In addition to orientation, the position of the lesion is important. Yamamoto introduced the concept of the glenoid track in which the integrity of the track and the location of the lesion can predict bony stability [17]. The authors defined the glenoid track as the contact patch between the superolateral aspect of the posterior humeral head and the glenoid when the arm is in abduction and external rotation. Larger and deeper Hill Sachs lesions are more likely to be engaging, with one study associating a decrease in stability once $25 \%$ of the humeral head is involved [18]. More recent studies have indicated the importance of the specific position within the track, with peripheral track lesions representing a subcritical but meaningful lesion [19]. Additionally, consideration must be given to the laxity of the soft tissue stabilizers surrounding the bony defect. Despite these advancements, there is no consensus with regard to the optimal measurement technique for humeral head bone loss.

Recent studies indicate that combined bone loss of the humeral head and the glenoid is a significant factor in evaluating treatment options and cause for failure. Even though each lesion fails to meet the individual threshold for critical bone loss, the osseous deficit can lead to instability, since an off-track lesion more readily engages with smaller glenoid lesions [20, 21]. A Hill Sachs lesion in an off-track position can amplify the effect of glenoid bone loss. Shaha et al. reported that the presence of an off-track Hill Sachs lesion can compromise an isolated arthroscopic Bankart repair, with a $75 \%$ failure rate [22]. A recent cadaveric study demonstrated that lesions involving as little as $8-15 \%$ of the glenoid combined with a medium-sized Hill Sachs lesion can produce recurrent instability following an isolated Bankart repair [23]. The glenoid track concept has proved useful in evaluating bipolar bone loss and guiding treatment.

\section{Treatment algorithm}

Of paramount importance is selection of the index procedure to treat anterior instability. Multiple studies report unacceptably high failure rates following revision arthroscopic soft tissue repair. Ryu and Ryu reported a $27 \%$ failure rate in their series with an isolated arthroscopic Bankart repair [2]. The addition of a remplissage did not improve these results; McCabe et al. reported a failure rate of $36 \%$ in this group [24]. Thus, it is important to select the optimal procedure at the primary surgery (• Fig. 2).

From the authors' experience, an isolated arthroscopic Bankart repair can be considered in patients with a small ontrack Hill Sachs lesion and less than 10\% glenoid bone loss. Exam under anesthesia should yield no more than $2+$ on load and shift. In their practice, this makes up the majority of the procedures for anterior stabilization. It is important to evaluate the quality of the capsulolabral tissue, since repeated dislocations can lead to labral degeneration and a patulous capsule [8, 25]. In 2005, Sugaya described arthroscopic repair of the bony Bankart lesion, which the authors agree with [26]. Following strict selection criteria and using a modern surgical technique, Leroux reported a recurrence rate of $8 \%$ following arthroscopic stabilization for contact athletes [27]. This low failure rate included procedures performed on patients without glenoid or humeral bone loss and utilized the lateral decubitus position with a minimum of three suture anchors.

If the Hill Sachs lesion engages with glenoid bone loss less than 15\%, an arthroscopic Bankart repair with remplissage is a reasonable option. Results thus far are promising. Boileau reported $98 \%$ stability with $90 \%$ of 41 patients returning to sport at a minimum 2-year follow-up [28]. Franceschi et al. compared 25 patients undergoing arthroscopic Bankart repair to 25 patients undergoing the same procedure plus a remplissage [29]. They reported a $20 \%$ recurrence rate in the Bankart group alone compared to none in the remplissage group. Nourissat et al. reported one-third of patients described posterosuperior shoulder pain but did not note range of motion deficits [30]. Other studies have noted a decrease in abduction between 2 and 8 degrees [31-34]. In a study of return to sports following remplissage, Garcia et al. reported $95.5 \%$ returning to full sports at 7 months; however, $65.5 \%$ of overhead throwers complained of decreased range of motion during throwing with an average loss of external rotation of 4.8 degrees [35]. As such, the authors recommend arthroscopic Bankart repair 
without remplissage in overhead athletes, since range of motion is critical to their sport.

Patients that present with a non-engaging Hill Sachs lesion with greater than $10 \%$ bone loss demonstrate inferior outcomes following arthroscopic Bankart repair $[4,5]$. The Latarjet has become very popular in the past decade for this clinical scenario, while open Bankart has fallen out of favor. Multiple reports support favorable outcomes following Latarjet [36-40]. A recent analysis of American Board of Orthopaedic Surgery (ABOS) case logs from 2004-2013 indicates a trend towards increased use of bone block procedures; however, the complication rate remained high at $20.8 \%$ [41]. Reported complications include axillary or musculocutaneous nerve palsy, infection, coracoid nonunion, failure of fixation, and increased risk of osteoarthritis. Additionally, Di Giacomo reported an average of 59.5\% osteolysis of the coracoid graft despite no recurrent dislocations, indicating that the bone block effect may not be the primary stabilizing force from the Latarjet [42]. In the revision setting following a failed Latarjet procedure, changes in the anatomic relationships of the musculocutaneous and axillary nerve may predispose them to injury [43]. Yang et al. noted that all of their complications were from patients that had failed prior shoulder stabilization surgery [44]. Shah et al. reported on 47 patients undergoing Latarjet and noted a trend towards higher prevalence of complication rates when the patient had undergone multiple prior shoulder surgeries [45]. Thus, the Latarjet is a technically demanding procedure that produces its best outcomes as a primary procedure. With this in mind, the authors believe a role remains in shoulder stabilization for open Bankart repair. They reserve this for young male collision athletes with a history of multiple dislocations and glenoid bone loss up to $15 \%$. Patients that have failed an arthroscopic Bankart are also indicated for open Bankart repair. The open procedure allows for double row fixation of the capsulolabral complex, capsular plication, and a dual capsular shift involving the inferior and

Obere Extremität 2021 · 16:16-21 https://doi.org/10.1007/s11678-021-00631-2

(c) The Author(s) 2021

R. Kakazu - M. R. LeVasseur · R. A. Arciero - A. D. Mazzocca

\section{State of the art for treatment of bony defects around anterior shoulder instability-the American perspective}

\section{Abstract}

While arthroscopic Bankart repair yields high success rates, bone loss on the glenoid or humeral head can portend a poor outcome. The authors recommend a thorough evaluation including computed tomography (CT) scanning to best evaluate the amount of bone loss. Multiple studies have shown that the outcomes of revision stabilization procedures are inferior to the respective primary procedure; thus, it is of paramount importance to select the correct index procedure to optimize patient outcome. The authors present the American perspective on treating shoulder instability. For patients with a small on-track Hill Sachs lesion and less than $10 \%$ glenoid bone loss, an isolated arthroscopic Bankart repair is appropriate. This procedure is also recommended for bony Bankart lesions, as well as in overhead throwing athletes. With an engaging Hill Sachs lesion and less than $15 \%$ glenoid bone loss, the authors recommend the addition of a remplissage to the arthroscopic Bankart repair. For patients with up to $15 \%$ bone loss or following a failed previous arthroscopic repair, the authors advocate for open Bankart repair. They recommend Latarjet in patients with a non-engaging Hill Sachs lesion greater than $15 \%$ bone loss. Patients with bone loss over $30 \%$ would benefit from bone grafting with iliac crest autograft or distal tibia allograft for stabilization. In summary, the authors believe that the index procedure provides an opportunity to optimize patient outcome and careful consideration of the treatment options is warranted.

Keywords

Shoulder dislocation · Hill Sachs lesion - Open Bankart - Glenoid bone loss - Chronic shoulder instability

\section{Neuester Stand der Behandlung knöcherner Defekte im Bereich der vorderen Schulterinstabilität - aus amerikanischer Sicht}

\section{Zusammenfassung}

Die Erfolgsrate des arthroskopischen BankartRepair ist hoch, ein Knochenverlust am Glenoid oder Humeruskopf kann jedoch auf ein schlechtes Outcome hindeuten. Die Autoren dieses Beitrags empfehlen eine eingehende Untersuchung einschließlich Computertomographie (CT), um das Ausmaß des Knochenverlusts optimal beurteilen zu können. In diversen Studien waren Revisionsoperationen zur Stabilisierung dem jeweiligen Primärverfahren bezüglich der Behandlungsergebnisse unterlegen. Daher ist die Wahl des besten Verfahrens für den Ersteingriff entscheidend für die Optimierung des Patientenoutcomes. Im vorliegenden Beitrag wird die Therapie der Schulterinstabilität aus amerikanischer Perspektive geschildert. Für Patienten mit kleiner Hill-Sachs-Läsion im Kontaktbereich (,on track") und weniger als $10 \%$ glenoidalem Knochenverlust eignet sich ein isolierter arthroskopischer Bankart-Repair. Dieses Verfahren wird auch für knöcherne BankartLäsionen empfohlen, zudem für Sportler, die Überkopfwürfe ausführen. Bei einer "engaging Hill Sachs lesion" und weniger als $15 \%$ glenoidalem Knochenverlust empfehlen die Autoren eine Remplissage zusätzlich zum arthroskopischen Bankart-Repair. Patienten mit bis zu 15\% Knochenverlust oder nach einer gescheiterten arthroskopischen Rekonstruktion sollten einem offenen BankartRepair unterzogen werden. Für Patienten mit "non-engaging Hill Sachs lesion" und über 15\% Knochenverlust empfehlen die Autoren das Latarjet-Verfahren. Patienten mit Knochenverlust über 30\% profitieren von einer Stabilisierung mit autologem Beckenkamm- oder allogenem distalem Tibiatransplantat. Zusammenfassend sind die Autoren der Meinung, dass der Ersteingriff eine Möglichkeit bietet, das Patientenoutcome zu optimieren. Daher ist eine sorgfältige Abwägung der Behandlungsoptionen erforderlich.

\section{Schlüsselwörter}

Schulterluxation · Hill-Sachs-Läsion · Offene Bankart-Operation - Glenoidaler Knochenverlust - Chronische Schulterinstabilität 


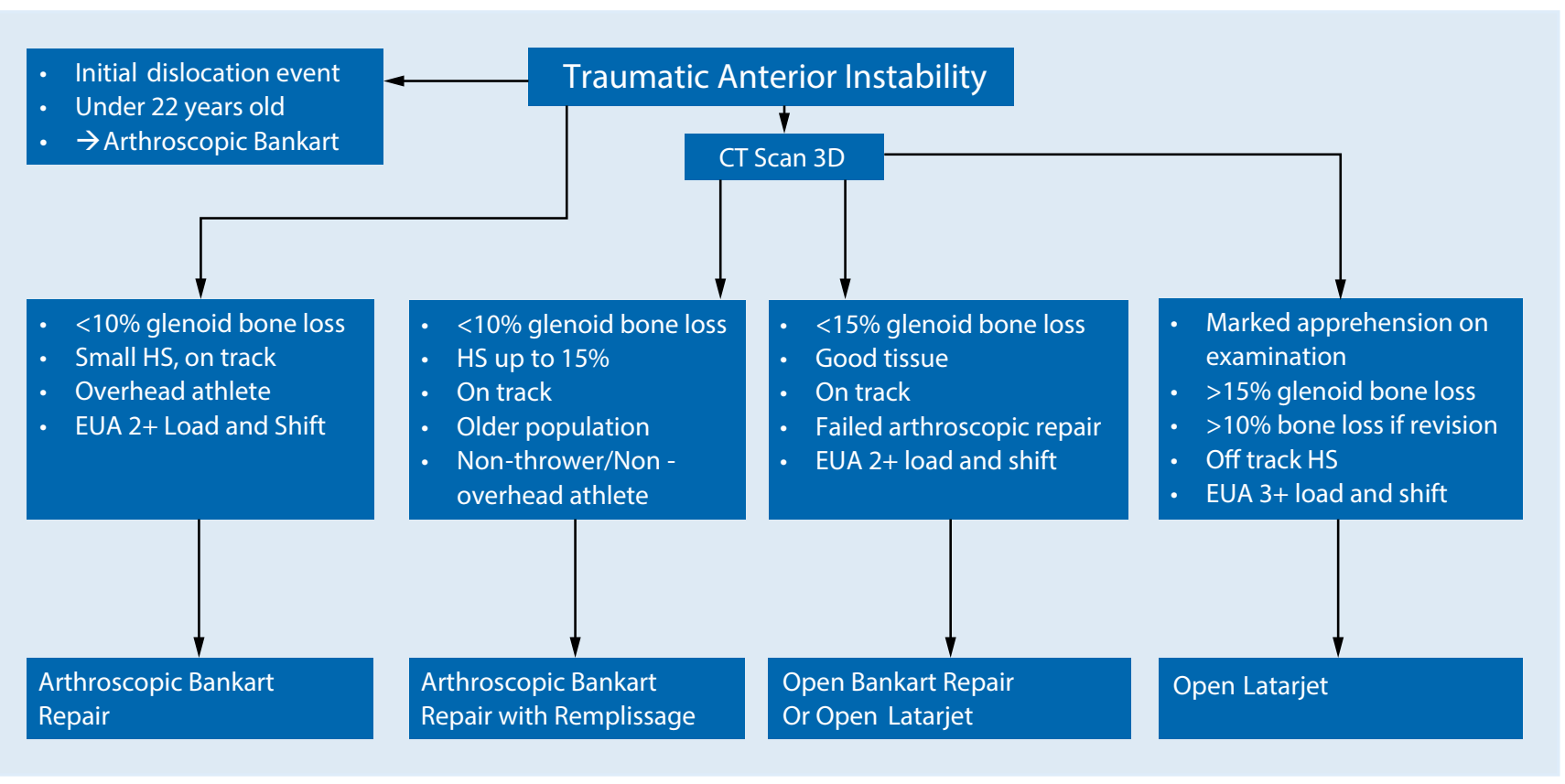

Fig. $2 \Delta$ Treatmentalgorithm for traumaticanteriorinstability. CT computed tomography, 3Dthree-dimensional, HSHill Sachs, EUA exam under anesthesia

superior leaflets to doubly reinforce the capsule. As such, a more robust repair is possible and suitable for the revision setting. The open Bankart has been a reliable option for over 60 years. Moroder et al. reported 20 year follow-up of open Bankart repairs, which resulted in $95 \%$ satisfaction and $15 \%$ recurrent instability; however, of those with recurrent instability, only $4.2 \%$ underwent reoperation [46]. More recently, Mohtadi compared open to arthroscopic Bankart repair and found equivalent quality of life scores but significantly reduced recurrence rates in the open group [47]. Thus, the authors believe that open Bankart repair is a reasonable option in this population.

Nonetheless, the Latarjet procedure remains an excellent option for cases that can overwhelm an open Bankart repair. The authors recommend Latarjet in patients with $>15 \%$ glenoid bone loss-lowering to $10 \%$ in the revision setting-with an off-track glenoid lesion. Additionally, the presence of marked apprehension on exam or a $3+$ load and shift on exam under anesthesia would also support the application of the Latarjet procedure.

From the author's experience, more severe bone loss over $30 \%$ would ben- efit from bone grafting with iliac crest autograft or distal tibia allograft. Iliac crest provides the healing advantage of autograft with the volume and contour needed to restore the glenoid. Disadvantages of this procedure include donor site morbidity, lack of articular cartilage on the graft, and potential for accelerated osteoarthritis due to contact with the humeral head [48, 49]. Distal tibia has been shown to closely match the contour of the glenoid as well as provide articular cartilage [50]. The authors reserve these procedures for severe cases of bone loss or the revision setting.

\section{Conclusions}

The treatment of anterior shoulder instability continues to evolve as surgical techniques are refined and longer-term studies are published. Multiple factors inform the treatment algorithm for anterior instability. Age as well as type and level of sport can drive the treatment decision. For example, the demands of the stable shoulder are different for the middle-aged patient looking to wash his or her hair compared to a young contact athlete. Additionally, the allure of a minimally invasive arthroscopic Bankart should be carefully weighed against the evidence supporting more invasive procedures. The primary stabilization procedure represents an opportunity to produce the best outcome for the patient in light of poorer outcomes and higher recurrence rates following revision procedures.

\section{Corresponding address}

Professor Augustus D. Mazzocca, MS MD

Department of Orthopaedic Surgery, University of Connecticut

263 Farmington Ave, 06030-4037 Farmington, CT, USA

mazzocca@uchc.edu

\section{Compliance with ethical guidelines}

Conflict of interest. R. Kakazu, M.R. LeVasseur, R.A. Arciero, and A.D. Mazzocca declare that they have no competing interests.

For this article no studies with human participants or animals were performed by any of the authors. All studies mentioned were in accordance with the ethical standards indicated in each case.

Open Access. This article is licensed under a Creative Commons Attribution 4.0 International License, which permits use, sharing, adaptation, distribution and reproduction in any medium or format, as long as you give appropriate credit to the original author(s) and the source, provide a link to the Creative Commons li- 
cence, and indicate if changes were made. The images or other third party material in this article are included in the article's Creative Commons licence, unless indicated otherwise in a credit line to the material. If material is not included in the article's Creative Commons licence and your intended use is not permitted by statutory regulation or exceeds the permitted use, you will need to obtain permission directly from the copyright holder. To view a copy of this licence, visit http://creativecommons.org/licenses/by/4.0/.

\section{References}

1. Burkhart SS, De Beer JF (2000) Traumatic glenohumeral bone defects and their relationship to failure of arthroscopic Bankart repairs. Arthrosc J Arthrosc Relat Surg 16(7):677-694. https://doi. org/10.1053/jars.2000.17715

2. Ryu RKN, Ryu JH (2011) Arthroscopic revision Bankart repair: a preliminary evaluation. Orthopedics 34(1):17. https://doi.org/10.3928/0147744720101123-11

3. Nakagawa S, luchi $R$, Hanai $H$, Hirose $T$, Mae $T$ (2019) The development process of bipolar bone defects from primary to recurrent instability in shoulders with traumatic anterior instability. Am J Sports Med 47(3):695-703. https://doi.org/10. $1177 / 0363546518819471$

4. Shaha JS, Cook JB, Song DJ et al (2015) Redefining "critical" bone loss in shoulder instability. Am J Sports Med 43(7):1719-1725. https://doi.org/10. 1177/0363546515578250

5. Dlckens JF, Owens BD, Cameron KL et al (2017) The effect of subcritical bone loss and exposure on recurrent instability after arthroscopic bankart repair in intercollegiate American football. Am J Sports Med 45(8):1769-1775. https://doi.org/10. 1177/0363546517704184

6. Waterman BR, Burns TC, McCriskin B, Kilcoyne K, Cameron KL, Owens BD (2014) Outcomes after bankart repair in a military population: predictors for surgical revision and long-term disability. Arthroscopy 30(2):172-177. https://doi.org/10. 1016/j.arthro.2013.11.004

7. Phadnis J, Arnold C, Elmorsy A, Flannery M (2015) Utility of the instability severity index score in predicting failure after arthroscopic anterior stabilization of the shoulder. Am J Sports Med 43(8):1983-1988. https://doi.org/10.1177/ 0363546515587083

8. Rugg CM, Hettrich CM, Ortiz S et al (2018) Surgical stabilization for first-time shoulder dislocators: a multicenter analysis. J Shoulder Elbow Surg. https://doi.org/10.1016/j.jse.2017.10.041

9. Kuhn JE (2010) A new classification system for shoulderinstability. BrJSportsMed 44(5):341-346. https://doi.org/10.1136/bjsm.2009.071183

10. Dickens JF, Slaven SE, Cameron KL et al (2019) Prospective evaluation of glenoid bone loss after first-time and recurrent anterior glenohumeral instabilityevents. Am JSports Med 47(5):1082-1089. https://doi.org/10.1177/0363546519831286

11. Owens BD, Nelson BJ, Duffey ML et al (2010) Pathoanatomy of first-time, traumatic, anterior glenohumeral subluxation events. J Bone Joint Surg Am 92(7):1605-1611. https://doi.org/10. 2106/JBJS.I.00851

12. Owens BD, Burns TC, Campbell SE, Svoboda SJ, Cameron KL (2013) Simplemethod of glenoid bone loss calculation using ipsilateral magnetic resonance imaging. Am J Sports Med 41(3):622-624. https://doi.org/10.1177/0363546512472325
13. Huijsmans PE, Haen PS, Kidd M, Dhert WJ, van der Hulst VPM, Willems WJ (2007) Quantification of a glenoid defect with three-dimensional computed tomography and magnetic resonance imaging: a cadaveric study. J Shoulder Elbow Surg 16(6):803-809. https://doi.org/10.1016/j.jse. 2007.02.115

14. Boileau P, Villalba M, Héry JY, Balg F, Ahrens $P$, Neyton L (2006) Risk factors for recurrence of shoulder instability after arthroscopic bankart repair. J Bone Joint Surg Am 88(8):1755-1763. https://doi.org/10.2106/JBJS.E.00817

15. Yamamoto N, Muraki T, Sperling JW, et al (2010) Stabilizing mechanism in bone-grafting of a large glenoid defect. J Bone Joint Surg Am 92(11):2059-2066. https://doi.org/10.2106/JBJS.I. 0026

16. Itoi E, Lee SB, Berglund LJ, Berge LL, An KN (2000) The effect of a glenoid defect on anteroinferior stability of the shoulder after Bankart repair: a cadaveric study. JBone Joint Surg Am 82(1):35-46 https://doi.org/10.2106/00004623-20000100000005

17. Yamamoto $\mathrm{N}$, Itoi $\mathrm{E}$, Abe $\mathrm{H}$ et al (2009) Effect of an anterior glenoid defect on anterior shoulder stability: a cadaveric study. Am J Sports Med 37(5):949-954. https://doi.org/10.1177/ 0363546508330139

18. Ahmed I, Ashton F, Robinson CM (2012) Arthroscopic Bankart repair and capsular shift for recurrent anterior shoulder instability: functional outcomes and identification of risk factors for recurrence. JBone Joint Surg Am 94(14):1308-1315 https://doi.org/10.2106/JBJS.J.01983

19. Yamamoto N, Shinagawa K, Hatta T, Itoi E (2020) Peripheral-track and central-track Hill-Sachs lesions: a new concept of assessing an on-track lesion. Am J Sports Med 48(1):33-38. https://doi. org/10.1177/0363546519886319

20. Trivedi S, Pomerantz ML, Gross D, Golijanan P, Provencher MT (2014) Shoulder instability in the setting of bipolar (glenoid and humeral head) bone loss: the glenoid track concept. Clin Orthop Relat Res 472(8):2352-2362. https://doi.org/10. 1007/s11999-014-3589-7

21. Di Giacomo G, Itoi E, Burkhart SS (2014) Evolving concept of bipolar bone loss and the hill-sachs lesion: from "engaging/non-engaging" lesion to "on-track/off-track" lesion. Arthroscopy 30(1):90-98. https://doi.org/10.1016/j.arthro. 2013.10.004

22. Shaha JS, Cook JB, Rowles DJ, Bottoni CR, Shaha SH, Tokish JM (2016) Clinical validation of the glenoid track concept in anterior glenohumeral instability. J Bone Joint Surg Am 98(22):1918-1923. https:// doi.org/10.2106/JBJS.15.01099

23. Arciero RA, Parrino A, Bernhardson AS et al (2015) The effect of a combined glenoid and Hill-Sachs defect on glenohumeral stability: a biomechanical cadaveric study using 3-dimensional modeling of 142 patients. Am J Sports Med 43(6):1422-1429. https://doi.org/10.1177/0363546515574677

24. McCabe MP, Weinberg D, Field LD, O'Brien MJ, Hobgood ER, Savoie FH (2014) Primary versus revision arthroscopic reconstruction with remplissage for shoulder instability with moderate bone loss. Arthroscopy 30(4):444-450. https://doi.org/10. 1016/j.arthro.2013.12.015

25. Habermeyer P, Gleyze P, Rickert M (1999) Evolution of lesions of the labrum-ligament complex in posttraumatic anterior shoulder instability: A prospective study. J Shoulder Elbow Surg 8(1):66-74. https://doi.org/10.1016/S10582746(99)90058-7
26. Sugaya H, Moriishi J, Kanisawa I, Tsuchiya A (2005) Arthroscopic osseous Bankart repair for chronicrecurrent traumaticanteriorglenohumeral instability. J Bone Joint Surg Am 87(8):1752-1760. https://doi.org/10.2106/JBJS.D.02204

27. Leroux TS, Saltzman BM, Meyer M et al (2017) The influence of evidence-based surgical indications and techniques on failure rates after Arthroscopic shoulder stabilization in the contact or collision athlete with anterior shoulder instability. Am J Sports Med 45(5):1218-1225. https://doi.org/10. 1177/0363546516663716

28. Boileau P, O'Shea K, Vargas P, Pinedo M, Old J, Zumstein M (2012) Anatomical and functional results after arthroscopic Hill-Sachs remplissage. J Bone Joint Surg Am 94(7):618-626. https://doi. org/10.2106/JBJS.K.00101

29. Franceschi F, Papalia R, Rizzello G et al (2012) Remplissage repair-new frontiers in the prevention of recurrent shoulder instability: a 2year follow-up comparative study. Am J Sports Med 40(11):2462-2469. https://doi.org/10.1177/ 0363546512458572

30. Nourissat G, Kilinc AS, Werther JR, Doursounian L (2011) A prospective, comparative, radiological, and clinical study of the influence of the "remplissage" procedure on shoulder range of motion after stabilization by arthroscopic bankart repair. Am JSports Med 39(10):2147-2152. https:// doi.org/10.1177/0363546511416315

31. Brilakis E, Avramidis G, Malahias M-A et al (2019) Long-term outcome of arthroscopic remplissage in addition to the classic Bankart repair for the management of recurrent anterior shoulder instability with engaging Hill-Sachs lesions. Knee Surg Sports Traumatol Arthrosc 27(1):305-313. https://doi.org/10.1007/s00167-018-5261-3

32. Buza JA, lyengar JJ, Anakwenze OA, Ahmad CS, Levine WN (2014) Arthroscopic Hill-Sachs remplissage: a systematic review. J Bone Joint Surg Am 96(7):549-555. https://doi.org/10.2106/JBJS. L.01760

33. Cho NS, Yoo JH, Juh HS, Rhee YG (2016) Anterior shoulder instability with engaging HillSachs defects: a comparison of arthroscopic Bankart repair with and without posterior capsulodesis. Knee Surg Sports Traumatol Arthrosc 24(12):3801-3808. https://doi.org/10. 1007/s00167-015-3686-5

34. Zhu Y-M, Lu Y, Zhang J, Shen J-W, Jiang C-Y (2011) Arthroscopic Bankart repair combined with remplissage technique for the treatment of anterior shoulder instability with engaging Hill-Sachs lesion: a report of 49 cases with a minimum 2-year follow-up. Am J Sports Med 39(8):1640-1647. https://doi.org/10.1177/ 0363546511400018

35. Garcia GH, Wu HH, Liu JN, Huffman GR, Kelly JD (2015) Outcomes of the Remplissage procedure and its effects on return to sports. Am J Sports Med 44(5):1124-1130. https://doi.org/10.1177/ 0363546515626199

36. Burkhart SS, De Beer JF, Barth JRH, Criswell T, Roberts C, Richards DP (2007) Results of modified Latarjet reconstruction in patients with Anteroinferior instability and significant bone loss. Arthroscopy 23(10):1033-1041. https://doi.org/ 10.1016/j.arthro.2007.08.009

37. Allain J, Goutallier D, Glorion C (1998) Long-term results of the Latarjet procedure for the treatment of anterior instability of the shoulder. J Bone Joint Surg Am 80(6):841-852. https://doi.org/10.2106/ 00004623-199806000-00008 
38. Bessière $C$, Trojani C, Carles M, Mehta SS, Boileau P (2014) The open Latarjet procedure is more reliable in terms of shoulder stability than arthroscopic Bankart repair. Clin Orthop Relat Res 472(8):2345-2351. https://doi.org/10.1007/ s11999-014-3550-9

39. Cerciello S, Edwards TB, Walch G (2012) Chronic anterior glenohumeral instability in soccer players: results for a series of 28 shoulders treated with the Latarjet procedure. J Orthop Traumatol 13(4):197-202. https://doi.org/10.1007/s10195012-0201-3

40. Hovelius L, Sandström B, Saebö M (2006) One hundred eighteen Bristow-Latarjet repairs for recurrent anterior dislocation of the shoulder prospectively followed for fifteen years: study II-the evolution of dislocation arthropathy. J Shoulder Elbow Surg 15(3):279-289. https://doi. org/10.1016/j.jse.2005.09.014

41. Degen RM, CampCL, Werner BC, Dines DM, Dines JS (2016) Trends in bone-block augmentation among recently trained orthopaedic surgeons treating anterior shoulder instability. J Bone Joint Surg Am 98(13):e56. https://doi.org/10.2106/JBJS.15. 01478

42. Di Giacomo G, Costantini A, De Gasperis N et al (2011) Coracoid graft osteolysis after the Latarjet procedure for anteroinferior shoulder instability: a computed tomography scan study of twenty-six patients. J Shoulder Elbow Surg 20(6):989-995. https://doi.org/10.1016/j.jse.2010.11.016

43. Freehill MT, Srikumaran U, Archer KR, McFarland EG, Petersen SA (2013) The Latarjet coracoid process transfer procedure: alterations in the neurovascular structures. J Shoulder Elbow Surg 22(5):695-700. https://doi.org/10.1016/j.jse. 2012.06.003

44. Yang JS, Mazzocca AD, Cote MP, Edgar CM, Arciero RA (2015) Recurrent anterior shoulder instability with combined bone loss. Am J Sports Med 44(4):922-932. https://doi.org/10.1177/ 0363546515623929

45. Shah AA, Butler RB, Romanowski J, Goel D, Karadagli D, Warner JJP (2012) Short-term complications of the Latarjet procedure. J Bone Joint Surg Am 94(6):495-501. https://doi.org/10. 2106/JBJS.J.01830

46. Moroder P, Odorizzi M, Pizzinini S, Demetz E, Resch H, Moroder P (2015) Open Bankart repair for the treatment of anterior shoulder instability without substantial osseous Glenoid defects: results after a minimum follow-up of twenty years. J Bone Joint Surg Am 97(17):1398-1405. https:// doi.org/10.2106/JBJS.N.01214

47. Mohtadi NG, Chan DS, Hollinshead RM et al (2014) A randomized clinical trial comparing open and Arthroscopic stabilization for recurrent traumatic anterior shoulder instability. J Bone Joint Surg Am 96(5):353-360. https://doi.org/10.2106/JBJS. L.01656

48. Moroder P, Blocher M, Auffarth A et al (2014) Clinical and computed tomography-radiologic outcome after bony glenoid augmentation in recurrent anterior shoulder instability without significant glenoid bone loss. J Shoulder Elbow Surg 23(3):420-426. https://doi.org/10.1016/j.jse. 2013.07.048

49. MyeroffC, Archdeacon M (2011) Autogenous bone graft: donor sites and techniques. JBone Joint Surg Am 93(23):2227-2236. https://doi.org/10.2106/ JBJS.J.01513

50. ProvencherMT, Ghodadra N, LeClere L, Solomon DJ, Romeo AA (2009) Anatomic osteochondral glenoidreconstruction for recurrent glenohumeral instability with glenoid deficiency using a distal tibia allograft. Arthroscopy 25(4):446-452. https:// doi.org/10.1016/j.arthro.2008.10.017 